\title{
Observation of the Effect of Salmon Calcitonin on Curing Chronic Obstructive Pulmonary Disease (COPD) with Osteoporosis \\ Ping GUI ${ }^{1}$ and Xiao-tao WANG $^{2, *}$
}

\author{
${ }^{1}$ Department of Respiratory medicine, Renmin Hospital, Hubei University of Medicine, \\ Shiyan, Hubei, China, 442000 \\ ${ }^{2}$ Department of Minimally Invasive Orthopedics, Renmin Hospital, Hubei University of \\ Medicine, Shiyan, Hubei, China, 442000 \\ ${ }^{*}$ Corresponding author: hubeiwenbo@qq.com
}

\begin{abstract}
Keywords: Salmon Calcitonin, Chronic Obstructive Pulmonary Disease (COPD), Osteoporosis, Curative Effect.
\end{abstract}

\begin{abstract}
Observe the application of salmon calcitonin to the curing of chronic obstructive pulmonary disease (COPD) with osteoporosis and evaluate its clinical effect. Method: take the 90 patients suffering COPD with osteoporosis who were admitted by this hospital from March, 2015 to June, 2017 as the research objects; divide them into two groups according to the filing sequence, control group and research group with 45 respective patients; give conventional therapy for the control group, and add salmon calcitonin on the basis of conventional therapy for the research group; the treatment periods of both groups were 8 weeks; finally, summarize and compare the treatment effect of in the two groups. Results: before treatment, the differences of patients in the two groups in the bone mineral density of lumbar vertebra (L2 4), ostealgia grading and pulmonary function grading had no statistical significance $(\mathrm{P}>0.05)$; but after treatment, all of them were improved $(\mathrm{P}<0.05)$, and the improvement effect in the research group was better than that in the control group obviously $(\mathrm{P}<0.05)$. Conclusion: the curative effect to apply salmon calcitonin to the treatment of COPD with osteoporosis was satisfactory, so salmon calcitonin was helpful to improve patients' bone mineral density and pulmonary function and ease ostealgia with important practical value.
\end{abstract}

\section{Introduction}

COPD is a group of common clinical respiratory diseases with high morbidity and a certain fatality rate. Osteoporosis (OP) is a main and common complication of COPD, which affects the patients' life quality and health seriously [1]. Taking Calcium Carbonate and Vitamin D3 Tablets is a common treatment method for this disease, but the reports in recent years showed that this method had some limitations [2]. In this research, we added salmon calcitonin into the treatment of this disease, in order to provide reference for the selection of clinic treatment plans. Now we have got satisfactory results as follows:

\section{General Data}

Take the 90 patients suffering COPD with osteoporosis who were admitted by this hospital from March, 2015 to June, 2017 as the research objects. Divide them into two groups according to the filing sequence, control group and research group with respective 45 patients. The control group contained 26 male patients and 19 female patients from 60 to 80 years old, the average age was $(68.1 \pm 6.1)$ years old; and their 
disease courses were between 8 to 15 years and the average disease course was (12.9 \pm 2.0$)$ years. The research course contained 24 male patients and 21 female patients from 60 to 80 years old, the average age was (68.3 \pm 5.9$)$ years old; and their disease courses were between 8 to 15 years and the average disease course was $(13.1 \pm 2.2)$ years. The differences of the two groups in the general data had no statistical significance $(\mathrm{P}>0.05)$, so they were comparable.

Inclusion criteria: (1) all patients took pulmonary function test after hospitalization and had chronic cough, expectoration, progressive dyspnea and other symptoms in varying degrees at grade I (FEV1 $\geq 80 \%$ of predicted value) and grade II (50\% $\leq$ FEV $1<80 \%$ of predicted value). Meanwhile, by laboratory examination, they had osteoporosis; (2) the research content had been approved by the ethical association of the hospital, and the patients and their family members were in know to sign the written consents voluntarily.

Exclusion criteria: (1) the patients suffering grade III and grade IV of COPD; (2) the patients having severe organ injury and cancers; (3) the patients with serious mental diseases; (4) the patients having bad treatment compliance and unable to cooperate with the treatment.

\section{Method}

Take conventional therapy for the control group, namely, take Calcium Carbonate and Vitamin D3 Tablets (manufacturer: Beijing Kangyuan Pharmaceutical Co., Ltd.; approval number: G.Y.Z.Z. H20153675), per os and chew, 1 tablet / once, once to twice / day, and at most 3 tablets / day.

Add Calcitonin Injection (manufacturer: Chengu List Pharmaceutical Co., Ltd.; approval number: G.Y.Z.Z. H20158635) into the conventional therapy for the reference group, subcutaneous injection or intramuscular injection, once /day. According to the severity degree of diseases, take 50 100IU / once or 100IU Alt. dieb. Adjust the dose according to individual need to avoid progressive bone loss; the treatment periods of both groups were 8 weeks.

\section{Observation Indexes}

(1) Take Challenger Dual-energy X-ray Absorptiometry (France DMS) to test the bone mineral density of lumbar vertebra $\left(\mathrm{L}_{2 \sim 4}\right)$ of the patients in both groups before and after treatment; (2) Use simple pain scale to grade the ostealgia of the patients in the two groups, the total score is 10 , and the higher the score is, the severer the pain is; (3) test the $1 \mathrm{~s}$ forced expiratory volume, maximum expiratory flow rate, maximum expiratory flow volume, functional residual capacity and other indexes of the patients in the two groups to evaluate the patients' pulmonary function.

\section{Statistical Method}

Take SPSS21.0 statistics software to evaluate the data in the research. When the differences of the sample data have statistical significance, $\mathrm{P}<0.05$; take " $\bar{x} \pm s$ " to express the normal measurement data and take t-test for the comparison between the groups. 


\section{Results}

\section{The Differences of the Two Groups in the Bone Mineral Density and Ostealgia Grading of the Patients before and after Treatment}

Before treatment, the differences of the two groups in bone mineral density of lumbar vertebra $\left(\mathrm{L}_{2 \sim 4}\right)$ and ostealgia grading of the patients had no statistical significance $(\mathrm{P}>0.05)$, but after treatment, all of them were improved $(\mathrm{P}<0.05)$, and the improvement effect in the research group was better than that in the control group obviously $(\mathrm{P}<0.05)$ (table 1$)$.

Table 1. The differences of the two groups in the bone mineral density and ostealgia grading of the

$$
\text { patients before and after treatment }(\bar{x} \pm s)
$$

\begin{tabular}{llll}
\hline Grouping & Time & $\begin{array}{l}\text { bone mineral density of } \\
\text { lumbar vertebra }\left(\mathrm{L}_{2 \sim 4}\right)\end{array}$ & $\begin{array}{l}\text { Ostealgia } \\
\text { grading } \\
(\mathrm{gcores})\end{array}$ \\
\hline Research & Before treatment & $0.653 \pm 0.539$ & $5.35 \pm 1.25$ \\
group & After treatment & $0.692 \pm 0.335^{* \#}$ & $2.20 \pm 0.77^{*} \#$ \\
Control & Before treatment & $0.654 \pm 0.550$ & $5.34 \pm 1.33$ \\
group & After treatment & $0.668 \pm 0.238^{*}$ & $3.62 \pm 0.92^{*}$ \\
\hline
\end{tabular}

Note: Compared with that before treatment, * means $<0.05$; compared with that in the control group, \# means $<0.05$.

\section{The Pulmonary Function of the Patients in the two Groups before and after Treatment}

Before treatment, the differences of the two groups in the pulmonary function of the patients had no statistical significance $(\mathrm{P}>0.05)$, but after treatment, all of them were improved $(\mathrm{P}<0.05)$, and the improvement effect in the research group was better than that in the control group obviously $(\mathrm{P}<0.05)($ table 2$)$.

Table 2. The pulmonary function of the patients in the two groups before and after treatment $(\bar{x} \pm s)$

\begin{tabular}{llllll}
\hline Grouping & Time & $\begin{array}{l}\text { 1s forced } \\
\text { expiratory } \\
\text { volume (L) }\end{array}$ & $\begin{array}{l}\text { Maximum } \\
\text { expiratory } \\
\text { flow rate } \\
\text { (L/s) }\end{array}$ & $\begin{array}{l}\text { Maximum } \\
\text { expiratory } \\
\text { flow } \\
\text { volume } \\
(\mathrm{L} / \mathrm{s})\end{array}$ & $\begin{array}{l}\text { Functional } \\
\text { residual } \\
\text { capacity } \\
(\mathrm{L})\end{array}$ \\
\hline $\begin{array}{l}\text { Research } \\
\text { group }\end{array}$ & $\begin{array}{l}\text { Before } \\
\text { treatment }\end{array}$ & $1.30 \pm 0.70$ & $3.30 \pm 1.62$ & $0.64 \pm 0.43$ & $4.88 \pm 1.63$ \\
& $\begin{array}{l}\text { After } \\
\text { treatment }\end{array}$ & $1.51 \pm 0.75$ & $3.68 \pm 1.82$ & $0.89 \pm 0.50$ & $4.28 \pm 1.30$ \\
$\begin{array}{l}\text { Control } \\
\text { group }\end{array}$ & $\begin{array}{l}\text { Before } \\
\text { treatment }\end{array}$ & $1.29 \pm 0.71$ & $3.29 \pm 1.70$ & $0.65 \pm 0.40$ & $4.89 \pm 1.65$ \\
& $\begin{array}{l}\text { After } \\
\text { treatment }\end{array}$ & $1.38 \pm 0.71$ & $3.44 \pm 1.32$ & $0.71 \pm 0.34$ & $4.44 \pm 1.20$ \\
\hline
\end{tabular}

Note: Compared with that before treatment, $*$ means $<0.05$; compared with that in the control group, \# means $<0.05$. 


\section{Discussion}

COPD has some obvious features, such as airflow obstruction and emphysema. After progression, the disease will lead to pulmonary heart disease, respiratory failure and other chronic diseases finally. The incidence of the disease is positively related to the abnormal inflammatory reaction caused by daily harmful gas and particles respired. The single disability rate and fatality rate of the disease are high. Osteoporosis is one of the main complications of COPD, with diversified causing factors and having obvious bone tissue calcification, calcium salt and matrix. Meanwhile, it has the feature that the bone tissue quantity in unit volume is reduced. Pain is the main clinical feature for patients [3]. When these two diseases coexist, the injury degree will become " $1+1>2$ ", which doesn't only affect the daily life of patients, but also increases the risk of fatality rate in direct proportion with the progression of disease [4].

Salmon calcitonin is one of main hormones to regulate calcium metabolism and control parathyroid hormone clinically, which has the good effect on lowering the bone and calcium loss for high-turnover bone diseases, such as deforming osteopathy, malignant osteolysis, osteoporosis and painful neuratrophy. The action mechanism is that, after injection, the medicine can restrain the bone cell viability, and stimulate bone cytomorphosis at the same time, and then increase the blood calcium concentration pathologically and reduce the excretion of urinary calcium and blood sodium absorbed in the kidney tubules by retaining osteolysis. In addition, the medicine can control the secretions of stomach and pancreas effectively in the condition that not to affect gastrointestinal peristalsis. The research report on the 80 patients suffering COPD with osteoporosis written by $\mathrm{Hu} \mathrm{Li}$ and Bai Yan [5] showed that, the effect to improve the bone mineral density of the patients in the research group by salmon calcitonin was obviously better than that in the control group by conventional therapy, and the differences had statistical significance $(\mathrm{P}<0.05)$, which verifies that the effect to treat old patients' COPD with osteoporosis by this medicine is satisfactory, and it is helpful to improve patients' bone mineral density. This is consistent with the results of this research.

Except that the curative effect of the medicine is clear, the research report written by He Haosen and Chen Jiaxin [6]showed that, after subcutaneous or intramuscular injection, the valid bioavailability of the medicine was more than $70 \%$, the blood concentration of most patients reached the peak within $1 \mathrm{~h}$, the elimination half-time occurred after about 70 90min, more than $95 \%$ of residual medicine was excreted by kidneys effectively, and the residual $2 \%$ was excluded by archetype. This verified that the residue in the body was less after using this medicine. Therefore, related untoward effects caused by medicine accumulation will not be triggered, but the verification of the index still needs to be further explained and supplemented by research.

In conclusion, the curative effect to apply salmon calcitonin to the treatment of COPD with osteoporosis is satisfactory, so salmon calcitonin is helpful to improve patient's bone mineral density and pulmonary function and ease ostealgia with important practical value. Moreover, the author suggests that, besides the targeted drug therapy, remove the causes, reduce inhale dust and chemicals inhalation, reduce indoor air pollution, take more exercise, breathing exercise and cold-tolerance exercise, take enough calcium and vitamin $\mathrm{D}$, examine the bone mineral density periodically, take psychotherapy, improve the immunologic function and take other comprehensive therapies are significant. In a word, the curative effect to apply salmon calcitonin to the treatment of COPD with osteoporosis is good, which will provide 
more effective treatment service for patients after the large sample and long-term researches are verified further.

\section{References}

[1] Fouda MA, Alhamad EH, Al-Hajjaj MS, Shaik SA, Alboukai AA, A study of chronic obstructive pulmonary disease-specific causes of osteoporosis with emphasis on the emphysema phenotype,12(2):101-106,(2017).

[2] Zheng Z, Qi Y, Xu X, Jiang H, Sputum mucin 1 is increased during the acute phase of chronic obstructive pulmonary disease exacerbation.J Thorac Dis,9(7):1873-1882,(2017).

[3] Moran JM, Pedrera Zamorano JD.Comment on "Assessment of Bone Mineral Density in Male Patients with Chronic Obstructive Pulmonary Disease by DXA and Quantitative Computed Tomography".Int J Endocrinol(2017).

[4] De la Rosa D, Martínez-Garcia MA, Giron RM,Clinical impact of chronic obstructive pulmonary disease on non-cystic fibrosis bronchiectasis. A study on 1,790 patients from the Spanish Bronchiectasis Historical Registry.PLoS One(2017).

[5] Hirai T.Osteoporosis in chronic obstructive pulmonary disease.Clin Calcium. 26(10):1393-1398,(2016).

[6] Visser EJ, Kwei PL.Salmon calcitonin in the treatment of post herpetic neuralgia.Anaesth Intensive Care,pp,668-671, (2006) . 